\title{
Are there sex differences in the brain basis of literacy related skills? Evidence from reading and spelling impairments after early unilateral brain damage
}

\author{
Uta Frith ${ }^{\mathrm{a}, *}$, Faraneh Vargha-Khadem ${ }^{\mathrm{b}}$ \\ ${ }^{a}$ Institute of Cognitive Neuroscience, University College London, 17 Queen Square, London WC1N 3AR, UK \\ ${ }^{\mathrm{b}}$ Developmental Cognitive Neuroscience Unit, Institute of Child Health, University College London, \\ Great Ormond Street Hospital for Children NHS Trust, Wolfson Centre, Mecklenburgh Square, London WC1N 2AP, UK
}

Received 1 June 2000; received in revised form 18 March 2001; accepted 3 April 2001

\begin{abstract}
Reading and spelling performance was analysed for a sample of 45 children with unilateral brain damage. Boys showed impairments only when the lesion was on the left, while girls showed no significant impairments when either hemisphere was affected. The results support the hypothesis that specialised substrates, which underlie literacy acquisition, have limited plasticity and may be more strongly lateralised to the left hemisphere in males than in females. C) 2001 Elsevier Science Ltd. All rights reserved.
\end{abstract}

Keywords: Literacy; Impairments; Unilateral brain damage

\section{Introduction}

Using existing data from a large scale neuropsychological study which was carried out during the 1980s in a children's hospital in Montreal [10,11], we tested the hypothesis that early brain damage in the left hemisphere may be more detrimental than right-hemisphere damage to the acquisition of alphabetic literacy. We expected this to be true for both sexes. However, there are some findings that are consistent with the hypothesis of stronger lateralisation of phonology in males than in females $[2,5,6,8]$. To the extent that early phonological skills predict later reading success $[1,4,7,9,12]$, a consequence would be a disruption of the smooth acquisition of literacy specifically in boys.

\section{Methods}

Data on reading and spelling were available on 53 children, 32 with left-hemisphere lesions (18 male, 14 female) and 21 with right-hemisphere lesions (13 male, 8 female). The patients, who were selected according to criteria described previously $[10,11]$, all had a measur-

\footnotetext{
* Corresponding author. Tel.: + 44-20-76791166.

E-mail address: u.frith@ucl.ac.uk (U. Frith).
}

able degree of hemiparesis, and the side of lesion was verified by $\mathrm{CT}$ scans. In 30 cases, the unilateral weakness became manifest during the first 6-9 months of life in the absence of an acute episode, and so the pathology was assumed to have occurred prenatally; in the remaining 15 cases the hemiplegia occurred after a well-defined neurological episode (e.g. cerebro-vascular accident, arteriovenous malformation and haemorrhage, low grade tumour, or trauma), with age at post-natal injury ranging from 2 months to 13.8 years. None of the patients suffered from an uncontrolled seizure disorder at the time they were investigated. About half the sample was French speaking, half English speaking. The age at testing ranged from 6 to 19 years. Mean age at testing and mean Wechsler IQs are shown in Table 1. There was no significant difference between any of the four groups in terms of IQ or age. A normal control group of 16 children, 8 girls and 8 boys were matched as far as possible to the patients for age, ability, and language background (half English, half French). The Durrell reading and spelling tests [3] were used in English and in French, after translation. The reading test involves reading aloud short passages of text, graded in difficulty. The assessment of reading retardation was based on the grade level achieved on the test compared to the grade the child 
Table 1

Ages and Wechsler IQ scores for the groups in the present comparison: mean (S.D.)

\begin{tabular}{|c|c|c|c|c|c|c|}
\hline Gender & Lesion side & $N$ & Age (year) & VIQ & $1+$ & FIQ \\
\hline \multicolumn{7}{|l|}{ Patients } \\
\hline \multirow[t]{2}{*}{ Female } & Left & 14 & $11(3)$ & $93(15)$ & $92(17)$ & 94 (13) \\
\hline & Right & 8 & $11(3)$ & $95(16)$ & 94 (14) & 94 (15) \\
\hline \multirow[t]{2}{*}{ Male } & Left & 18 & $10(3)$ & 97 (16) & 95 (17) & $96(15)$ \\
\hline & Right & 13 & $11(3)$ & 100 (19) & $101(13)$ & $101(15)$ \\
\hline \multicolumn{7}{|l|}{ Controls } \\
\hline Female & None & 8 & $10(2)$ & 96 (11) & $102(7)$ & 99 (9) \\
\hline Male & None & 8 & $11(3)$ & 105 (13) & $105(11)$ & $106(12)$ \\
\hline
\end{tabular}


should have achieved for his or her age. Thus, children were categorised as scoring either at least 1 year below grade level or at grade level and above. Given the wide individual variation in the children's age and ability and in elapsed time between injury and testing, this relatively coarse classification seemed the most appropriate as it avoids spurious precision.

The spelling test involved dictation of 20 common words, some with regular (back, spend), but most with irregular spelling (e.g. money, necessary), and 15 rare and unfamiliar words with regular spelling (e.g. carpolite, intervent). Regularity and irregularity of spelling was similar in both French and English versions of the test. Spelling of the unfamiliar words was scored in terms of phonetic accuracy, i.e., responses had to show acceptable phoneme-to-grapheme correspondences. Spelling of the familiar words had to be orthographically correct. Misspellings were due to lack of phoneme-grapheme rules in the case of the unfamiliar words, and due also to lack of word specific knowledge in the case of familiar words. Children below the age of eight and children with VIQ scores below 80 were given a shorter list of easier words to spell, but the list of unfamiliar words was the same. Thus, percentages rather than raw scores were used.

\section{Results}

Preliminary ANOVAs showed no significant effect $(P>0.05)$ of language used (French vs English), nor of timing of brain damage (pre or postnatally). Data were therefore collapsed across these variables. Reading and spelling results are shown in Table 2 .

Spelling achievement in the patient groups was analysed by ANOVA separately for the familiar and unfamiliar words with the factors gender and side of lesion. There was no main effect of gender or side of lesion in either case, but there was a significant gender by side of lesion interaction $(F=9.63 ; \mathrm{df}=1,38 ; P<$ 0.01 , for familiar words, and $F=4.97 ; \mathrm{df}=1,28 ; P<$ 0.05 , for unfamiliar words). Left-sided damage produced a greater impairment in boys than in girls, and right-sided damage produced a greater impairment in girls than in boys. Fig. 1 illustrates this interaction.

For comparison with the control groups four $t$-test were carried out on the spelling scores, combined for the two types of words. These indicated that boys with left-sided lesions performed significantly less well than the boys in the control group $(t=2.52, \mathrm{df}=22, P<$ 0.02 ), whereas the boys with right-hemisphere lesions performed very similarly to the controls $(t=0.47$, df

Table 1

Ages and Wechsler IQ scores for the groups in the present comparison: mean (S.D.)

\begin{tabular}{|c|c|c|c|c|c|c|}
\hline Gender & Lesion side & $N$ & Age (year) & VIQ & PIQ & FIQ \\
\hline \multicolumn{7}{|l|}{ Patients } \\
\hline \multirow[t]{2}{*}{ Female } & Left & 14 & $11(3)$ & $93(15)$ & $92(17)$ & 94 (13) \\
\hline & Right & 8 & $11(3)$ & $95(16)$ & 94 (14) & 94 (15) \\
\hline \multirow[t]{2}{*}{ Male } & Left & 18 & $10(3)$ & 97 (16) & 95 (17) & $96(15)$ \\
\hline & Right & 13 & $11(3)$ & $100(19)$ & $101(13)$ & $101(15)$ \\
\hline \multicolumn{7}{|l|}{ Controls } \\
\hline Female & None & 8 & $10(2)$ & $96(11)$ & $102(7)$ & 99 (9) \\
\hline Male & None & 8 & $11(3)$ & 105 (13) & $105(11)$ & $106(12)$ \\
\hline
\end{tabular}

Table 2

Reading and spelling performance in children with unilateral lesions and age and IQ matched comparison groups ${ }^{\mathrm{a}}$

\begin{tabular}{|c|c|c|c|c|c|c|}
\hline Gender & Lesion side & $N$ & $\begin{array}{l}\% \text { Subjects reading at grade } \\
\text { level }\end{array}$ & $N$ & Familiar words spelled correctly & Unfamiliar words spelled correctly \\
\hline \multicolumn{7}{|l|}{ Patients } \\
\hline \multirow[t]{2}{*}{ Female } & Left & 9 & 78 & 13 & $70(32)$ & $37(27)$ \\
\hline & Right & 8 & 75 & 8 & $54(29)$ & $27(18)$ \\
\hline \multirow[t]{2}{*}{ Male } & Left & 15 & 47 & 19 & $44(32)$ & $25(25)$ \\
\hline & Right & 13 & 85 & 13 & $71(16)$ & $51(25)$ \\
\hline \multicolumn{7}{|l|}{ Controls } \\
\hline Female & None & 8 & 88 & 8 & 75 (19) & $58(23)$ \\
\hline Male & None & 8 & 75 & 8 & $64(29)$ & $60(30)$ \\
\hline
\end{tabular}

\footnotetext{
${ }^{\text {a }}$ Reading data presented in terms of percentage of subjects; spelling data presented for familiar $(\max =20)$ and unfamiliar words $(\mathrm{max}=15)$ in terms of mean percentage words spelled correctly.
} 


\section{Familiar and unfamiliar words spelled correctly (\%)}

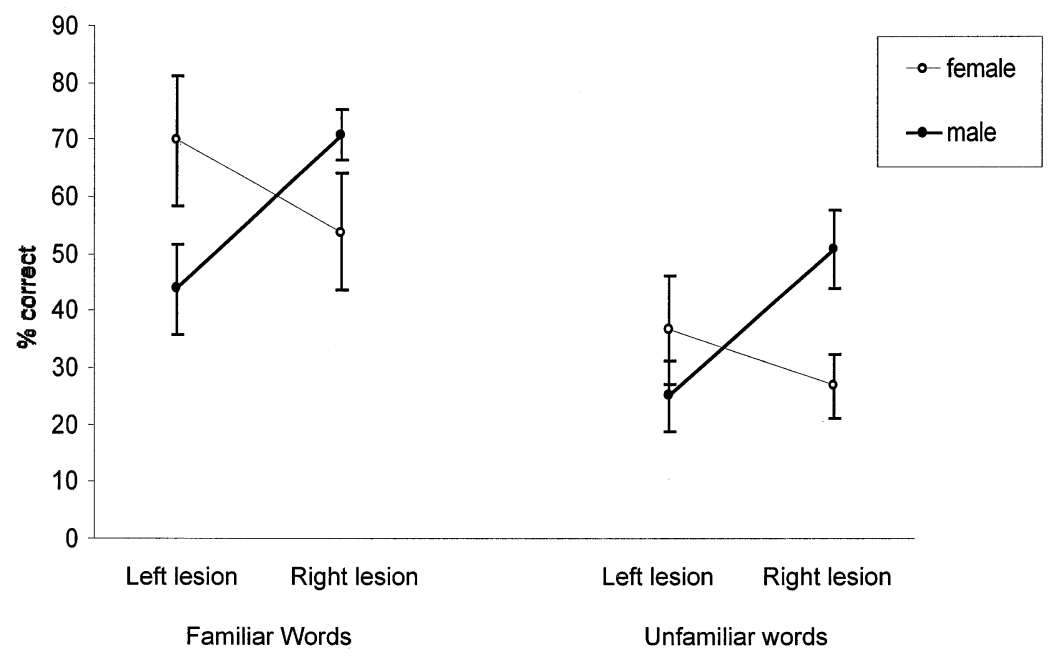

Fig. 1.

$=19$, ns). The girls with left-sided lesions performed similarly to the control group of girls, and there was no significant differences between the girls with right-sided lesions and the controls $(t=1.72, \mathrm{df}=15, \mathrm{~ns})$.

Table 2 also shows the results for reading achievement, that is, the proportion of children classified as either reading impaired, or as normally achieving. A $\chi^{2}$ test for the four patient groups $\left(\chi^{2}=3.28, P<0.03\right.$, one-tailed) suggested that more boys with left-hemisphere damage were adversely affected than those with right-hemisphere damage, while hemispheric side of damage made little difference to the girls. Although the pattern of results for reading is remarkably similar to the results for spelling, it should be noted that few data points were available for analysis, and that the level of significance is low.

\section{Discussion}

The present sample of children with unilateral brain damage was extremely heterogeneous in terms of age at injury, age at testing, and language spoken, and the data available for analysis were very limited. We also had limited power to detect differences in some comparisons where participant numbers were small. Hence the results must be treated with caution. They suggest, however, that reading and spelling impairment was related specifically to left-sided damage in boys. Importantly, this effect was found not only for familiar but also unfamiliar words, which were scored in terms of appropriate use of phoneme-to-grapheme correspondences. This supports the hypothesis that phonological impairment might be responsible for the literacy deficit that was tapped by the present measures. In contrast, no specific effect was found for girls with left-sided lesions in the present sample. If anything, right-sided lesions were somewhat more deleterious. It should be noted, however, that the girls with right-sided lesions were not significantly impaired relative to the girls in the control group.

These results are consistent with the existing evidence that phonological processes tend to show stronger left lateralisation in males [8]. While previous work on sex differences in brain organisation for language functions addressed this issue in adults, the present study extends the finding to children, and suggests that sexual dimorphism for at least some processes underlying literacy may emerge early in life.

The results have implications for the question of neural plasticity. Comparison with the normal control group showed that the boys with right-sided lesions were unimpaired in reading and spelling performance, in contrast to the boys with left-hemisphere lesions, and in contrast to the girls. Although the data are not informative on individual compensatory success or failure, reading and spelling achievement for the patient group as a whole was clearly affected by the laterality of these early lesions.

\section{References}

[1] Brady S, Shankweiler D. Phonological processes in literacy. Hillsdale, NJ: Lawrence Erlbaum, 1991.

[2] Bryden M. An overview of the dichotic listening procedure and its relation to cerebral organisation. In: Hugdahl K, editor. Handbook of dichotic listening. Chichester: Wiley, 1988:1-43.

[3] Durrell DD. Durrell analysis of reading difficulty. New York: Harcourt Brace, 1955.

[4] Goswami U, Bryant P. Phonological skills and learning to read. Hove: Lawrence Erlbaum, 1990.

[5] Harasty J, Double KL, Halliday GM, Kril JJ, McRitchie DA. Language associated cortical regions are propor- 
tionally larger in the female brain. Archives of Neurology 1997;54:171-6.

[6] Lukatela G, Carello C, Savic M, Turvey MT. Hemispheric asymmetries in phonological processing. Neuropsychologia 1986;24:341-50.

[7] Rack J, Hulme C, Snowling MJ, Wightman J. The role of phonology in young children learning to read words: the direct mapping hypothesis. Journal of Experimental Child Psychology 1994;57:42-71.

[8] Shaywitz BA, Shaywitz S, Pugh KR, Constable TR, Skudlarski $P$, et al. Sex differences in the functional organization of the brain for language. Nature 1995;373:607-9.
[9] Share DL. Phonological recoding and self-teaching: sine qua non of reading acquisition. Cognition 1995;55:151-218.

[10] Vargha-Khadem F, Isaacs E, Van der werf S, Robb S, Wilson J. Development of intelligence and memory in children with hemiplegic cerebral palsy. Brain 1992;115:315-29.

[11] Vargha-Khadem F, O'Gorman AM, Watters GV. Aphasia and handedness in relation to hemispheric side, age at injury and severity of cerebral lesion during childhood. Brain 1985;108:677-96.

[12] Wagner RK, Torgeson LK. The nature of phonological processing and its causal role in the acquisition of reading skills. Psychological Bulletin 1987;101:192-212. 